\title{
Práticas socioeducativas do/a orientador/a à adolescentes autores/as de ato
} infracional

\author{
Socio-educational practices o the supervisor to adolescent authors of infractional act \\ Prácticas socioeducativas del supervisor a autores adolescentes de acto infraccional
}

Recebido: 10/08/2021 | Revisado: 13/08/2021 | Aceito: 14/08/2021 | Publicado: 16/08/2021

Rafael Garcia Campos

ORCID: https://orcid.org/0000-0002-5836-0645 Senac São Paulo, Brasil

E-mail: rafael.gcampos@outlook.com

Rubia Fernanda Quinelatto

ORCID: https://orcid.org/0000-0002-0827-3869 Universidade Federal de São Carlos, Brasil E-mail: rubiafq@gmail.com

\begin{abstract}
Resumo
O presente estudo investigou o impacto das práticas socioeducativas do/a orientador/a de adolescentes em conflito com a lei no estabelecimento das medidas de médio e longo prazo de adolescentes autores/as de ato infracional. Tratase de um estudo de natureza qualitativa, de caráter descritivo-exploratório com a colaboração de 13 adolescentes, com idade entre 12 e 18 anos incompletos. Os dados foram coletados por meio de questionário de caracterização sociofamiliar e entrevistas individuais com roteiro semiestruturado. O roteiro de entrevista contemplou questões norteadoras, que abordaram as experiências vivenciadas pelos/as adolescentes durante e depois do cumprimento da medida socioeducativa. Os resultados apontaram categorias significativas para a auto-organização dos/as adolescentes na ocasião da medida e, neste artigo, o foco está na categoria: a relação com o/a Orientador/a de medida socioeducativa. Constatou-se, assim, que para as práticas socioeducativas de liberdade assistida seja efetiva e reconhecida pelos/as adolescentes, familiares e sociedade de um modo geral, faz-se necessário contar com a articulação do trabalho em rede social, poder público e participação assídua do judiciário, a fim de garantir os direitos básicos do/a adolescente assistido/a e de sua família.
\end{abstract}

Palavras-chave: Socioeducação; Liberdade assistida; Medidas socioeducativas.

\begin{abstract}
This study investigated the impact of the socio-educational practices of the counselor of adolescents in conflict with the law on the establishment of medium and long-term measures for adolescents who committed an offense. This is a qualitative, descriptive-exploratory study with the collaboration of 13 adolescents, aged between 12 and 18 years old. Data were collected through a socio-familial characterization questionnaire and individual interviews with a semistructured script. The interview script included guiding questions, which addressed the experiences lived by the adolescents during and after the fulfillment of the socio-educational measure. The results pointed to significant categories for the adolescents' self-organization at the time of the measurement and, in this article, the focus is on the category: the relationship with the supervisor of socio-educational measurement. It was found, therefore, that for the socio-educational practices of assisted freedom to be effective and recognized by adolescents, families and society in general, it is necessary to rely on the articulation of social network work, public authorities and assiduous participation of the judiciary, in order to guarantee the basic rights of the assisted adolescent and his/her family.
\end{abstract}

Keywords: Socioeducation; Assisted freedom; Educational measures.

\section{Resumen}

Este estudio investigó el impacto de las prácticas socioeducativas de la consejera de adolescentes en conflicto con la ley en el establecimiento de medidas de mediano y largo plazo para los adolescentes que cometieron un delito. Se trata de un estudio cualitativo, descriptivo-exploratorio que contó con la colaboración de 13 adolescentes, con edades comprendidas entre los 12 y los 18 años. Los datos fueron recolectados a través de un cuestionario de caracterización sociofamiliar y entrevistas individuales con un guión semiestructurado. El guión de la entrevista incluyó preguntas orientadoras, que abordaron las experiencias vividas por los adolescentes durante y después del cumplimiento de la medida socioeducativa. Los resultados apuntan a categorías significativas para la autoorganización de los adolescentes en el momento de la medición y, en este artículo, el foco está en la categoría: la relación con el supervisor de la medición socioeducativa. Se encontró, por tanto, que para que las prácticas socioeducativas de libertad asistida sean efectivas y reconocidas por los adolescentes, las familias y la sociedad en general, es necesario contar con la 
articulación del trabajo en red social, las autoridades públicas y la participación asidua de la población. poder judicial, a fin de garantizar los derechos básicos del adolescente asistido y su familia.

Palabras clave: Socioeducación; Libertad assistida; Medidas educativas.

\section{Introdução}

Os/as adolescentes em conflito com a lei, possuem características psicossociais e econômicas vulneráveis, tais como uso abusivo de álcool e outras drogas, baixa escolarização, residências em bairros/comunidades de classe baixa, renda familiar precária, além da ausência de apoio familiar, uma vez que o ciclo familiar também se encontra em situação de vulnerabilidade social. Constata-se que os/as adolescentes que entraram em conflito com a lei estudados/as por Coelho e Rosa (2013), são desassistidos por parte do Estado, da família e da sociedade. Nesse sentido, torna-se essencial analisar o contexto relacional de do/a adolescente para melhor entendê-lo/a (Quinelatto, 2015b; Conceição, 2017; Campos, 2017).

Os sistemas principais em que o/a adolescente está inserido/a são constituídos por meio da família, grupo de pares e da escola. Nesta esteira, a criminalidade é um sistema bastante presente nos ambientes de convivência desses/as adolescentes infratores/as, e, para além, são reflexos de uma sociedade discriminatória (Colombarolli et al., 2014).

A ausência de critérios sistemáticos para direcionar as tomadas de decisão pode, por um lado, levar a Justiça da Vara da Infância e Juventude a aplicar medidas inadequadas ao/a adolescente, o que pode não ter qualquer efeito ou repercussão negativa para os/as adolescentes, desconsiderando os déficits desenvolvimentais e as inúmeras vulnerabilidades que se encontram expostos/as. As decisões são tomadas apenas em critérios jurídicos, no qual pondera-se tão somente à gravidade do delito por ele/a causado/a e se é reincidente ou não no sistema de justiça (Maruschi; Estevão; Bazon, 2013)

O/a adolescente ao ser designado/a para cumprimento de medida socioeducativa deve considerar a gravidade do ato infracional, o contexto em que este adolescente está inserido/a e sua capacidade de conseguir concluir a medida de forma que esta sirva como orientação e formação educacional e não apenas punitiva (Campos et al., 2021).

De acordo com Jimenez (2014) é possível reconhecer práticas socioeducativas que pioram a saúde psicológica, emocional e física de adolescentes infratores/as: as práticas de masculinidade/hipermasculinidade, a desonra, violências praticadas no tráfico de entorpecentes e nas abordagens policiais e a crença de ser um/a criminoso/a. Os comportamentos agressivos parecem se confundir com práticas de orientadores/as de medidas socioeducativas caracterizadas pela masculinidade ou hipermasculinidade de tal forma que provavelmente não são entendidos pelos/as adolescentes como violência, mas sim como comportamentos naturalizados, que fazem parte do cotidiano e o exercício dos mesmos tem o sentido de compor uma posição no grupo, respeitado pela coragem, virilidade, frieza. Os/as orientadores/as que atuam nas medidas socioeducativas precisam de intervenção com foco educacional, com propósito de disseminar a comunicação e atos não violentos. Haja vista, que comportamentos agressivos são práticas, não raras, observadas pelos/as próprios/as orientadores/as ao relacionar-se com os/as adolescentes, desatentando-se que reagem da forma que são tratados/as (Jimenez, 2014).

\section{Práticas socioeducativas de orientadores/as à adolescentes autores de ato infracional}

As práticas socioeducativas de orientadores/as destinada aos/as adolescentes devem ser realizadas com a participação familiar, uma vez que essa fase da vida traz transformações biopsicossociais, que envolvem todo o contexto a que este/a adolescente está inserido/a, afinal, é um todo relacional colocado sempre em um contexto social abrangente, que também contém subsistemas nos quais constitui uns e está fora de outros (Jimenez, 2014; Costa et al., 2007).

No Brasil, mais de $60 \%$ dos/as adolescentes em cumprimento das medidas socioeducativas de internação são originários/as de classes menos favorecidas economicamente, segundo Silva e Araújo (2013). Ao praticarem atos infracionais, os/as adolescentes entram em contato com o sistema judiciário, que pode representar os limites que procuram, de forma que 
os/as juízes/as reconhecem tornar a figura paterna/protetora de autoridade e orientação do "certo e errado" (Silva \& Araújo, 2013).

Costa et al. (2007), afirma que a abordagem aos problemas dos/as adolescentes seja feita inicialmente a partir da família, pois está inserida em meio que recebe interferências internas e externas, que passam por modificações constantemente. A visão ampliada sugerida procura identificar a estrutura familiar, padrões de relacionamentos rotineiros e nível hierárquico, com objetivo de compreender as relações de poder, os vínculos, a divisão de responsabilidades, os meios de comunicação entre os membros da família.

As crianças e adolescentes brasileiros/as só tiveram legalmente seus direitos garantidos, individuais e coletivos, por meio do Estatuto da Criança e do Adolescente (Brasil, 1990), a vista disso, em qualquer circunstância, não podendo ser objeto de violência, negligência, discriminação, exploração, crueldade e humilhação, aplicando se for o caso, a punição, segundo a lei (Silva et al., 2015).

Um exemplo recorrente da falácia discriminatória é o/a adolescente adentrar a gestão escolar para solicitar sua matrícula para dar continuidade aos estudos obrigatórios e gratuitos por lei e a gestão escolar nega-se em matriculá-lo/a. Como também outras dificuldades em exercer atividade remunerada para seu autossustento e sustento da sua família, acesso à saúde, moradia (Quinelatto Caparrós, 2013a).

As práticas socioeducativas de orientadores/as devem respeitar as fases de desenvolvimento integral do/a adolescente, considerando suas potencialidades, subjetividades, capacidades e limitações, assegurando a particularidade no seu acompanhamento. Sendo assim, o Plano Individual de Atendimento - PIA, é um instrumento pedagógico fundamental para garantir a equidade no processo socioeducativo (Brasil, 2006).

O Plano Individual de Atendimento é um mecanismo pedagógico que gerencia e planifica as ações a serem cumpridas para viabilizar a proteção integral (Brasil, 1990), a (re)inserção familiar e comunitária e a autonomia de adolescentes distantes dos cuidados parentais e sob proteção de serviços de acolhimento estatal (Brasil, 1988). O estabelecimento de definições para o PIA são muitos, uma vez que cada prática socioeducativa co-responsabilizará suas ações junto aos/as adolescentes autores/as de ato infracional, com vistas a metas alcançáveis, de acordo com o público-alvo e os objetivos socioeducativos. A elaboração do PIA, instrumento imprescindível para a organização da oferta dos serviços, é uma das atividades primordiais para a execução do trabalho socioeducativo pelas equipes de referência, ou seja, orientadores/as de medida socioeducativa.

O Plano Individual de Atendimento é promulgado a partir da lei do Sistema Nacional de Atendimento Socioeducativo - SINASE (Brasil, 2006) e inaugura a condição de estruturação do plano de atendimento individualizado, com vistas a abarcar as especificidades de cada adolescente, considerando as imbricações de sua trajetória, escolarização e amplitude social, especialmente no que tange à circunstância individualizadora de desenvolvimento biopsicossocial. Pelo exposto, por meio do PIA, assegura-se o acesso aos direitos fundamentais preconizados pela política de proteção integral, estabelecida no Estatuto da Criança e do Adolescente (Brasil, 1990), bem como direciona a cada adolescente infrator/a, a individualização da medida socioeducativa, viabilizando seu cumprimento, na perspectiva do mundo público dos direitos.

Destarte, o entendimento o Sistema Nacional de Atendimento Socioeducativo (Brasil, 2006) permite uma visualização detalhada dos aspectos relativos aos conceitos e procedimentos do PIA:

[...] a elaboração do Plano Individual de Atendimento constitui-se numa importante ferramenta no acompanhamento da evolução pessoal e social do adolescente e na conquista de metas e compromissos pactuados com esse adolescente e sua família durante o cumprimento da medida socioeducativa. A elaboração do PIA se inicia na acolhida do adolescente no programa de atendimento e o requisito básico para sua elaboração é a realização do diagnóstico polidimensional por meio de intervenções técnicas junto ao adolescente e sua família, nas áreas: jurídica, saúde, psicólogo, social e pedagógica (Brasil, 2006, p.52). 
Costa et al. (2011), sinaliza que o relatório psicossocial, uma das práticas de orientadores/as de medidas, não deve ser elaborado somente como avaliativo, todavia de forma a desenvolver a humanização aos/as adolescentes que dependem das decisões judiciais e promovem intervenção psicossocial de forma equitativa. O relatório precisa, portanto, ser elaborado com prudência, a fim de que não seja mais um instrumento de controle e rotulação de adolescentes em fase de experimentação de papéis e formas de inserção no mundo.

A execução das práticas de medidas socioeducativas estabelece à equipe técnica desafios que englobam a compreensão do ambiente em que vivem os/as adolescentes, como também os fatores acrescidos para a autoria do ato infracional.

Coelho e Rosa (2013), apontam estudos que discutem especificamente sobre adolescentes em cumprimento da medida em meio aberto são estritamente restringidos/as. Já as práticas socioeducativas de medidas em regime fechado (privação de liberdade) devem ser fundamentadas em três princípios básicos: brevidade, excepcionalidade e respeito à condição peculiar de pessoa em desenvolvimento. Porém, o que se constata é o descrédito das instituições responsáveis pela prática socioeducativa de privação de liberdade.

É sabido que não se alcança o seu real objetivo de ressocializar, vivenciar trocas de experiências, aumentando focos de tensão permanente, gerando rebeliões, fugas, mortes e reincidência ao delito (Estevam et al., 2009). Assim surgem dúvidas sobre a eficácia das práticas socioeducativas: ela de fato está cumprindo seu papel ressocializador, conforme preconizado pela lei?

Outrossim, é pertinente analisar a estrutura física das Unidades de atendimento de internação provisória, de semiliberdade e de internação, que deve contribuir com as práticas e os projetos pedagógicos específicos dos programas de atendimentos, devendo atender as normas de conforto ambiental, de ergonomia, de humanização e de segurança. É necessário que as estruturas físicas das unidades de internação inibam a ideia de formação de complexos, devendo respeitar o número de até quarenta adolescentes em cada Unidade de atendimento, conforme determinação da resolução de n 46/96 (Brasil, 2006).

Para além, questiona-se a atribuição da medida socioeducativa mais grave (privação de liberdade), por tal ação, não raro, ser incompatível com o grau do ato infracional praticado, gerando lotação, escassez dos recursos humanos (mão de obra), financeiros e infra estruturais. Reitera-se que o/a adolescente precisa ser protagonista de sua história, participar do processo de construção de sua formação e do seu saber contando com a ajuda dos/as envolvidos nesse processo. Os/as adolescentes e seus familiares não são simples espectadores e objetos das políticas, são partícipes principais, comprometidos consigo e com sua família, a fim de construir um processo civilizatório, humanizador e ético (Souza Neto \& Centolanza, 2010).

O fortalecimento da convivência familiar, comunitária e a avaliação, são fatores favoráveis à ressocialização de adolescentes em conflito com a lei, sendo essencial propiciar ambiente reflexivo para questionamento do sentido ético da vida, a fim de contribuir para o abandono da opressão, para, então, tomar decisões acertadas, sem uma prática fundada na vigilância e na punição (Passamani \& Rosa, 2009).

A justiça deve estabelecer condições para o desenvolvimento das práticas socioeducativas, a fim de que o/a adolescente resgate sua perspectiva de ser em processo de formação, dando espaço e voz para ele/a e sua família, esclarecendo o sentido da medida disciplinar. Nossas leis precisam reaver sua autoridade de recriação, para que o/a adolescente em conflito com a lei adquira relações sociais embasadas no respeito e perceber seu lugar no meio social (Costa et al., 2011).

No que tange ao quesito "satisfação" dos/as orientadores/as de práticas socioeducativas, verifica-se descontentamento por não se sentirem valorizados, sem incentivos e oportunidade de ascensão profissional e, não raro, pelo fato de não acreditarem na proposta pedagógica e educacional (Campos \& Machado, 2021).

Indícios dessa "insatisfação" pelo trabalho são a não elaboração por parte da equipe de referência de orientadores/as (assistente social, pedagogo, psicólogo, agente educacional e segurança) dos registros sistemáticos das abordagens e 
acompanhamentos aos/as adolescentes, contido no Plano Individual de Atendimento, a elaboração de relatórios psicossociais com punho avaliativo beneficiando tão somente o juizado em sua decisão, descaracterizando, por sua vez, a real proposta do relatório, quando deveria servir como instrumento rico do processo jurídico sobre a etapa de desenvolvimento do/a adolescente e o aumento dos casos de tumultos e rebeliões dentro das Fundações CASA.

Compete aos/as orientadores/as de medidas socioeducativas na execução das práticas, a incumbência de proteção, na garantia do conjunto de direitos e educar oportunizando a inclusão deste/a adolescente em conflito com a lei na vida social, de forma a estimular o protagonismo de sua trajetória de vida (Brasil, 2006).

\section{O Caminhar Metodológico}

O estudo é de natureza qualitativa, de caráter descritivo-exploratório, desvelando a complexidade dos fenômenos envolvidos nas relações sociais e culturais de adolescentes em conflito com a lei. Tal modalidade de pesquisa trouxe à luz a interação entre o ambiente e as pessoas, em sua forma holística e não reduzidos a variáveis (Minayo, 2004).

Participaram da pesquisa 13 adolescentes - 12 do sexo masculino 1 do sexo feminino - com idade entre 12 e 18 anos incompletos, obedecendo aos critérios de inclusão: adolescentes em cumprimento da medida de liberdade assistida que concordaram em participar da pesquisa e que estivessem na fase final do processo. A fase de extinção da medida socioeducativa é compreendida como conclusiva, é o período em que o/a adolescente está em avaliação, aguardando o posicionamento do judiciário para aprovação e, possível, arquivamento processual. Com vistas à ocultação de identidade, são apresentados/as neste artigo por uma letra e a idade correspondente.

Os dados foram coletados utilizando como técnica o questionário de caracterização sociofamiliar e, posteriormente, com entrevistas individuais com roteiro semiestruturado. Contemplaram-se aspectos que abordaram as experiências vivenciadas pelos/as adolescentes durante e após o cumprimento da medida socioeducativa, as entrevistas foram agendadas antecipadamente com responsável legal e o/a adolescente. Para análise dos dados foi utilizada a análise de conteúdo de Bardin (2011) conceituada como um conjunto de técnicas para análise de comunicações de expressão, de relações, temática e a análise da enunciação.

\section{Resultados e Discussão}

Pelos depoimentos elucubrados neste artigo, os/as adolescentes se autointitulam indignos de direitos e a sociedade, não raro, declaram a autoria do ato infracional como uma prática de violência e, em situações diversas, acredita paradoxalmente que a resposta seja a aplicação de mais violência para combater o delito, o que é incongruente (Coelho \& Rosa, 2013).

Torna-se essencial abarcar o contexto relacional do/a adolescente para melhor entendê-lo/a. Os principais sistemas em que o/a adolescente está inserido/a são constituídos por meio da família, grupo de pares e da escola. Destaca-se que, a criminalidade é um sistema bastante presente nos ambientes de convivência dos/as adolescentes infratores/as, e, além disso, são reflexos de uma sociedade opressora (Colombarolli et al., 2014). Ainda nessa perspectiva Silva e Soares (2020, p. 7-8), afirmam que no âmbito educativo "As escolas como receptoras dessas políticas acabam por avançar no processo de exclusão, uma vez que as políticas nacionais estão cada vez mais alinhadas às organizações internacionais [...]”. Os autores desvelam um posicionamento escolar que vai de encontro às políticas públicas de inclusão social.

De acordo com Solfa (2008) as trajetórias dos/as adolescentes em conflito com a lei descortinam a condição de vulnerabilidade, que permite compreendê-los/as em situação de desproteção total, como parte de uma zona em que os vínculos pessoais e sociais estão fragilizados e/ou inexistem, igualmente a linha de direitos públicos. Assim, seu desenvolvimento pleno e integral encontra-se comprometido. Posicionados/as em condição de desfiliação, há a iminência de perda de vínculos sociais, 
relacionais e, consequentemente, o risco da inexistência social. Tal fragilidade é caracterizada tanto pela desproteção de direitos básicos, fundamentais, como pela exposição aos diferentes tipos de violência a que esses adolescentes estão submetidos.

O adolescente (B., 16 anos), é reincidente e afirma que a medida socioeducativa em liberdade assistida (LA), ajudoulhe a refletir sobre seu ato infracional e se posicionar de uma forma contrária a anterior. "Ah... euиu... (pausa) não ligava pra nada, sabe... não tava nem aí pras consequências... Ah... eu fumava maconha na escola memo... na porta da escola... não tava nem aí... mas hoje em dia, "xééé".. não passo nem perto de maconha... (pausa) quando tem gente que fuma maconha assim... eu não tenho preconceito, sabe... mas... (pausa) perto de mim... eu já saio de perto... A medida me ajudou, né... porque agora eu tô na escola... agora eu tô fazendo curso... tô assim, né... agora tô tentando arrumar um emprego..."

É fundamental a importância da atuação do/a profissional que realiza o atendimento individual em que deve ser estabelecida aos/as adolescentes, condições à sua conduta, direcionando atividades pré-estabelecidas, estimulando o convívio familiar, planejando sua vida escolar e profissional, com vistas a oportunizar elementos para sua ressocialização na sociedade. Este é mais um dos dilemas em torno do Estatuto da Criança e do Adolescente, que prevê que crianças e adolescentes frequentem o ensino básico. O Estatuto, em seu artigo $n^{\circ} 53$, estabelece que "[...] a criança e o adolescente têm direito à educação, visando ao pleno desenvolvimento de sua pessoa, preparo para o exercício da cidadania e qualificação para o trabalho" (Brasil, 1990). Para isso deve ter assegurada a igualdade de condições para o acesso e permanência na escola, contudo isso não é uma realidade à todas as crianças e adolescentes brasileiros/as.

Para Quinelatto Caparrós (2013a, p. 38) fica claro que "Por uma série de negligências, como a violação do direito à escola, dificuldade de acesso a cursos, descaso no atendimento à saúde, muitas crianças e jovens vivenciam o mundo do crime, conhecendo suas facilidades e dissabores [...]”. Tal comportamento deixará cicatrizes na trajetória de vida dos/as adolescentes e, por conseguinte, a consequência social: a liberdade vigiada para aqueles/as que se encontram em conflito com a lei.

No século XXI, os valores são fortemente consolidados a favor do capital pelo próprio sistema educacional, no qual a escola serve a estrutura capitalista. Torna-se urgente a formação crítica dos/as alunos/as que seja capaz de tencionar, colocar em suspeita o poder capitalista, mesmo que com pequenos avanços.

Desde a origem da escola, em meados do século XVIII, segue presente nos setores da sociedade as Organizações Sociais - ONGs, movimentos e redes solidárias na área da educação em geral, atravessando a ditadura militar, muitas vezes, clandestinamente, para atuar pela redemocratização do Estado, construindo em conjunto a perspectiva acessível, o que evidencia as limitações de uma sociedade que reforça a marginalização social (Machado, 2012).

Ainda no século XXI a sociedade burguesa, dominante na internalização de valores consolidados a favor do capital, não apoia o sistema educacional regular. É importante salientar a relevância estratégica da concepção mais abrangente de educação, uma vez que o processo contínuo de aprendizagem se constitui, para além das instituições educacionais regulares. Neste ponto, tais processos não podem ser manipulados e controlados de maneira instantânea pela estrutura educacional regular, legalmente resguardada e sancionada (Mészáros, 2008; Freire, 2013b, 2015c).

Ao pensar a Educação na perspectiva da luta emancipatória, não poderia esquecer de restabelecer os vínculos entre educação e trabalho "[...] digam-me onde está o trabalho em um tipo de sociedade e eu the direi onde está a educação". As determinações universais do capital interferem profundamente em cada âmbito particular, com influências na educação, não apenas nas instituições educacionais formais (Mészáros, 2008, p. 17).

Tanto na história da educação brasileira como os processos de escolarização são marcados pelos contrastes da sociedade moderna. Segundo Del Pino et al. (2012), convivemos com duas escolas que coexistem no mesmo espaço: uma que se coloca como a dona da verdade, não percebendo a existência de processos formativos para além dos seus muros; a outra, se pretende democrática, mas valida a trajetória daqueles/as que provêm das classes dominantes. Ambas estão apartadas da 
construção de um projeto de educação popular, com vistas a garantir o direito igualitário e de todos/as à Educação (Del Pino et al., 2012).

Para o adolescente (B., 16 anos), as elucubrações dadas pelo/a orientador/a que o atende têm sido importantes e têm feito diferença na forma dele lidar com as situações. "No atendimento a gente conversa se eu me dou bem com a minha mãe... eu falo que eu me dou bem com ela... ah... é tudo no papo, sabe... (pausa) só pra saber do dia-a-dia meu... (pausa) mas anda tudo normal meu dia-a-dia... tranquilo... O atendimento tem me ajudado né...Sobre a escola memo... a escola... "vish"... eu não gostava nem de passar na porta da escola... Não tinha nenhuma... aí hoje em dia estudando... terminando os estudo... Ah... ela falou que ia ser melhor pra minha vida... deu uns conselho pra mim... que ia ser melhor pra mim... que é bom terminar os estudo também... ai bateu na minha cabeça isso ai e eu resolvi terminar o estudo... fazer alguma coisa da vida, né...”

Pondera o adolescente que ao ser designado para o cumprimento da medida de liberdade assistida, no primeiro momento rejeitou, mas logo foi proposta uma oportunidade para retornar aos estudos, no qual compreendeu a necessidade descumprimento da medida de liberdade assistida. Relata que antes mesmo de voltar a cumprir a medida não pensava em agir e nem se importava com as consequências.

Segundo Gonçalves Filho (1988, p.98) "A criança sofre, o adolescente sofre. De onde vem, então, a saudade e a ternura pelos anos juvenis? Talvez porque nossa fraqueza fosse uma força latente e em nós houvesse o germe de uma plenitude a se realizar". É neste cruzar de sentimentos e lembranças, que as pessoas se nutrem simbolicamente da lembrança de episódios fragmentados, envolvendo indivíduos a quem se destina algum tipo de emoção, sentimento bom ou mal.

O autor traça um paralelo acerca do oposto, o desenraizamento, que por sua vez "[...] é a mais perigosa doença das sociedades humanas [...], ou caem numa inércia de alma quase equivalente à morte [...] ou se lançam numa atividade que tende sempre a desenraizar, muitas vezes por métodos violentíssimos [...]” (Gonçalves Filho, 1988, p.102).

Reorganizar os cuidados básicos na vida, além de favorecer uma boa saúde, contribui para novos hábitos e rotinas na vida cotidiana, que auxiliam na organização da vida social (Ferreira \& Pereira, 2012).

Observou-se que os/as adolescentes que buscavam retomar os estudos e ingressar no mercado de trabalho e não tiveram sucesso, foram conduzidos/as a nova fase de auto desorganização de suas vidas e reincidência na criminalidade.

O sujeito deve ser o protagonista de sua história, atuando no processo de construção de sua formação e do seu saber, contando com a ajuda dos envolvidos nesse processo. Não devem ser simples espectadores e objetos das políticas públicas, mas sim um sujeito autônomo, engajado consigo e com sua família para construir um processo civilizatório e ético (Neto \& Centolanza, 2010).

Para os adolescentes (B., 17 anos e G., 16), as práticas socioeducativas dadas pelos/as orientadores/as nos atendimentos os auxiliaram em seu dia a dia, visto que diminuíram as constantes discussões domiciliares, ao retratar que são bem recebidos pela orientadora que os atendem e que se não fosse pela ajuda dela, eles não tinham voltado a estudar.

O adolescente J., 17 anos, explica que é reincidente. Já cumpriu a medida de internação dentro da Fundação CASA, e agora é assistido pela medida de liberdade assistida. Relata perceber mudança significativa em sua vida. "Ah... o que mais mиdои ет тіт... foi... еи те... (раиsa) еи me... responsabilizo mais, né... agora, antes eu não tinha responsabilidade nenhuma... antes de eu vir assinar esse negócio aqui... agora eu tenho um compromisso de vim assinar aqui... de ter responsabilidade de estudar... fazer curso... porque é a melhora pra mim também, né...."

Assim, deve-se ressaltar que as práticas dos/as orientadores/as de medidas devem ser relacionadas à educação, com objetivo de mudança na vida desses/as adolescentes em conflito com a lei. Sendo assim, deve ser encarada com um objetivo de transformação de rota, responsabilizando-os/as, ao mesmo tempo em oferece oportunidades, oficinas e cursos eficazes, em direção à (re)construção de seu projeto de vida (Coelho \& Rosa, 2013). 
No que tange à Educação, o ensino médio por ser a última fase da escola unitária, deve ser planejado e, como proposta, consolidar os valores fundamentais do humanismo, como a autodisciplina intelectual e autonomia moral necessárias a uma posterior especialização, seja de caráter científico ou prático-produtivo. O ensino e o aprendizado dos métodos criativos na ciência e na vida devem começar nesta última fase da escola (Gramsci, 2000).

À rigor, o SINASE é documento norteador para o atendimento socioeducativo, sendo estruturado por princípios, condutas e ações jurídicas, políticas financeiras e administrativas, presentes no âmbito do atendimento com os/as adolescentes autores/as de ato infracional, expressados a partir da apuração do ato até a execução das medidas socioeducativas. É o documento regulador das diretrizes e seus eixos estratégicos para o estabelecimento e a execução das medidas socioeducativas em meio aberto e fechado. Insta declarar que a normativa das diretrizes não é sinônimo de padronização das formas de operacionalização do trabalho no cotidiano do programa de medidas socioeducativas, pelo contrário, faz-se necessário que o trabalho educativo e orientativo seja de caráter contemplativo às demandas do/a adolescente (Brasil, 2006).

Pelo exposto, as práticas dos/as orientadores/as das medidas socioeducativas, embora estruturadas sob a via do trato legal, possuem uma condução também de natureza pedagógica, que necessita ser reafirmada e efetivada como tal (Brasil, 2006).

O/a adolescente deve ter elementos concretos que o/a auxilie a abandonar a trajetória de opressão, ao participar do processo de construção de sua formação e do seu saber contando com a ajuda dos/as envolvidos/as neste processo. Os/as adolescentes e seus familiares não podem ser espectadores e objetos das políticas não efetivadas, para além, protagonistas comprometidos/as consigo e seus familiares, a fim de construir um processo civilizatório (Neto \& Centolanza, 2010).

Verifica-se que mesmo sendo portador/a explícito/a do direito à educação, previsto na legislação (Brasil, 1988, 1990, 2006) sua garantia para os/as adolescentes em cumprimento de medidas socioeducativas ainda sofre restrições em suas tentativas de acesso, contrariando a perspectiva de direito integral adquirido e a irreal tendência de democratização do acesso à educação.

Dessa forma, ao realizarem suas práticas socioeducativas nos atendimentos com efetividade, o/a orientador/a alcançará bons resultados, como expressado pelo adolescente (J., 17 anos). "O atendimento é bom... nóis conversa... ela pergunta se eu melhorei... o que que eu penso em fazer daqui dois ano... três ano... me ajuda bastante...Me ajuda a melhorar cada vez mais... deixar essas coisas pra trás e pensar no futuro meu e da minha família...”. É perceptível, pelas ricas falas dos/as depoentes autores/as de ato infracional, que as práticas socioeducativas programadas para adolescentes em conflito com a lei são determinantes no processo de (re)socialização, visto que propõe o (re)pensar das relações ocorridas em ambientes de liberdade vigiada.

O mesmo aconteceu com o adolescente (M., 17 anos) ao relatar que sua vida se transformou ao cumprir a medida de liberdade assistida. Minha vida mudou... se eu não tivesse vindo pra cá... essas horas tava lá na rua ainda... fumando maconha...

No presente estudo, nos adolescentes reincidentes, foi notório que a família se tornou um alto fator de risco, sendo que na amostra de quatro (4) adolescentes reincidentes, três (3) eram filhos de pais separados e possuíam histórico familiar comprometido com atos infracionais e criminais, além de abandono e indiferença dos familiares/pais.

Neste artigo os fatores de riscos associados à reincidência de autoria de ato infracional são decorrentes de consumo variado de algum tipo de droga ilícita, demonstrando que o/a adolescente, fica propenso a vulnerabilidades devido ao sustento do vício, bem como o pertencimento à estrutura familiar que poderá ser um fator de proteção ou risco.

Para a efetivação das práticas socioeducativas de liberdade assistida há a necessidade de articulação do trabalho em rede social, poder público e participação assídua do judiciário, a fim de garantir os direitos básicos do/a adolescente assistido/a 
e sua família, com objetivo de apoiar a estruturação de vida escolar e profissional, proporcionar elementos para sua (re)inserção social.

Pelo exposto, contribui-se com discussões acerca da prática educacional dentro de ambiente de controle de liberdade e colabora com os/as orientadores/as de medidas na busca por práticas alternativas, para além de uma questão metodológica, mas como uma questão ética e política, que pressupõe um posicionamento político-pedagógico, pois educar exige a ação intencional, com permanentes tomadas de decisão (Freire, 2001a).

Freire (2001a, p.25) apresenta a prática educativa libertadora como socialmente transformadora, para um mundo mais humano e humanizador, "É preciso assumir realmente a politicidade da educação. [...] Não posso reconhecer os limites da prática educativo-política em que me envolvo se não sei, se não estou claro em face de a favor de quem prático". Orientadores/as necessitam ter o compromisso de promover práticas que auxiliem no despertar de um diálogo interior e constante entre o valioso bem da liberdade e o da disciplina, que tenham condições de exercitarem o quanto antes a escolha dos seus caminhos e que exerçam sua cidadania com responsabilidade.

Não é possível separar os conteúdos da realidade, ambos caminham juntos e buscam o desvelamento crítico do mundo, fazendo da prática educativa uma prática política, intencional, que deve pautar-se pela ação e reflexão, concebida como práxis (Freire, 2001a).

\section{4. À Guisa das Considerações Finais}

Aos/as orientadores/as que atuam na medida de liberdade assistida, entende-se que precisam se apropriar do papel socioeducativo que possuem no processo de ressocialização dos/as adolescentes em cumprimento da medida. Ao depender do atendimento estruturado, conduzido e elaborado de acordo com a proposta SINASE (Brasil, 2006) e real necessidade desse/a adolescente assistido/a, poderá ser a diferença no processo de auto-organização. É fundamental o acompanhamento e recolocação desse/a adolescente na escola, garantindo seu direito de estudar e condições para que obtenha bom desempenho escolar, conforme estabelecido legalmente. Assim como exercer seu direito de proteção integral e obter a oportunidade de preparo para o trabalho lícito, viabilizando cursos de capacitação profissional com títulos e horários que atendam aos/as adolescentes e ao mercado de trabalho, não apenas ocupá-los/as com atividades diversas, como cursos de crochê, bordado e pintura.

Visto o trabalho proporcionar transformações na autonomia e inserção social, como apontado por adolescentes que exerciam atividade remunerada, verifica-se a aquisição de confiança pessoal e respeito familiar. Sendo assim, o/a adolescente poderá se tornar um/a sujeito/a autônomo/a, crítico e sabido dos seus direitos e deveres, abandonando a opressão ao construir um novo projeto de vida. Caso contrário, o/a adolescente permanecerá na criminalidade, sem expectativas, desconsiderando a real importância da medida de liberdade assistida.

Cabe às famílias dos/as adolescentes assistidos/as e a toda a comunidade, participar e intervir para tomadas de decisão conscientes, reflexivas e autônomas, para que junto se integre a proposta das medidas socioeducativas e exija dos poderes públicos direitos fundamentais para o desenvolvimento físico, mental e moral. Assim, o que nos propomos, enquanto pesquisador/a é a construção de conhecimentos que possam viabilizar o processo de reflexão sobre a prática socioeducativa, em relação ao seu trabalho educativo com adolescentes autores/as de ato infracional e ao espaço em que atuam.

Vale ressaltar a importância do judiciário ao estabelecer a medida socioeducativa ao/a adolescente, que seja compatível com seu ato infracional, objetivando seu histórico de vida e sua possibilidade de cumpri-la.

Os resultados da presente investigação, comprometidos com o rigor científico, almejam contribuir para melhor conhecimento do temário e com a área da Educação, na medida em que oferece subsídios para analisar os índices brasileiros, 
no que tange ao acompanhamento e proposição de políticas públicas socioeducativas, referentes ao atendimento de adolescentes em conflito com a lei.

Este artigo não se conclui tão somente nas reflexões propostas, faz-se necessário a continuidade de estudos na área, a fim de que as práticas socioeducativas, as Políticas Públicas e os Direitos Humanos possam ser revistos e efetivados em diferentes contextos históricos, uma vez que o ser oprimido/a social é uma constante na realidade brasileira.

\section{Referências}

Brasil. (1988). Constituição da República Federativa do Brasil de 1988. Presidência da República.

Brasil. (1990). Estatuto da Criança e do Adolescente. Lei no 8.069 de 13 de julho de 1990. Dispõe sobre o Estatuto da Criança e do Adolescente e dá outras providências. Senado Federal.

Brasil. (2006). Sistema Nacional de Atendimento Socioeducativo - SINASE. Secretaria Especial de Direitos Humanos. CONANDA.

Campos, R. G. \& Machado, D. F. (2021). Revisão Integrativa: Adolescentes Autores/as de ato infracional no Brasil. Temas em Educação, $30,167-184$.

Campos, R. G., Machado, D. F., Quinelatto, R. F., \& Conceição, W. L. da. (2021). The impact of the socio-educational measure for freedom assisted in the self-organization of the youth's life project in conflict with the law. Research, Society and Development, 10, e9910514792. 10.33448/rsd-v10i5.14792. Disponível em: https://rsdjournal.org/index.php/rsd/article/view/14792.

Campos, R. G. (2017). Auto-organização na construção de projeto de vida pelo adolescente em ressocialização. 99 fls. Dissertação (Mestrado em Saúde Coletiva).: Universidade Estadual Paulista.

Coelho, B. I. \& Rosa, E. M. (2013). Ato Infracional e Medida Socioeducativa: Representações de Adolescentes em L.A. Psicologia \& Sociedade, 25(1): 163$173 \mathrm{p}$.

Colombarolli, M. S., Souza e Silva, K. de S., Becker, M. A. d’Á., \& Katsurayama, M. (2014). Proposta de redução da idade penal: visão dos profissionais da psicologia. Psicol. Argum., 32(77), 19-26.

Conceição, W. L. da. (2017). Histórias de vidas que se unem: a professora, o professor e os [elos com os] jovens infratores. 136 fls. Tese (Doutorado em Educação) - Campinas: Universidade Estadual de Campinas, 2017. http://www.repositorio.unicamp.br/handle/REPOSIP/322308.

Costa, L. F., Penso, M. A., Sudbrack, M. F. O., \& Jacobina, O. M. P. (2011). Adolescente em conflito com a lei: o relatório psicossocial como ferramenta para promoção do desenvolvimento. Psicologia em Estudo, 16, 379-387.

Del Pino, M. A. B., Porto, G. C., Katrein, B. H. S., Rodrigues, T. C., Brizolara, R. M. R., \& Lapuente, J. S. M. (2012). A exclusão escolar nos anos iniciais: a passagem do ensino fundamental de oito para nove anos. In: IX ANPEd Sul - Seminário de Pesquisa em Educação da Região Sul, 2012, Caxias do Sul. IX ANPEd Sul - Seminário de Pesquisa em Educação da Região Sul. Caxias do Sul: Editora Universitária UCS, 1. 1-16.

Estevam, I. D., Coutinho, M. da P. de L., \& Araújo, L. F. de. (2009). Os desafios da prática socioeducativa de privação de liberdade em adolescentes em conflito com a lei: Ressocialização ou exclusão social? PSICO, Porta Alegre, PUCRS, 40, 64-72.

Ferreira, M. S. de C., \& Pereira, M. A. O. (2012). O Cuidado em Saúde Mental: a escuta de pacientes egressos de um Hospital Dia. Rev. bras. enf., 65.

Freire, P. (2001a). Política e educação: ensaios. (5a ed.), Coleção Questões de Nossa Época. Cortez.

Freire, P. (2013b). Pedagogia da autonomia: saberes necessários à prática educativa. (44a ed.), Paz e Terra.

Freire, P. (2015c). Educação como prática da liberdade. (28a ed.), Paz e Terra.

Gramsci, A. (1957). The formation of intellectuals. In: GRAMSCI, Antonio. The modern prince and other writings. Londres: Lawrence and Wishart. 118-125.

Gonçalves Filho, J. M. (1988). Olhar e memória. In: NOVAES, Adauto (Org.). O olhar. Companhia das Letras, 95-124.

Jimenez, L. (2014). Você já está manjado: a saúde de adolescentes em conflito com a lei. Psicologia Política, 14. 535-549.

Machado, É. (2012). As relações entre a Pedagogia Social e a Educação Popular no Brasil. Revista Diálogos, 18.

Maruschi, M. C., Estevão, R., \& Bazon, M. R. (2013). Aplicação de Medidas Socioeducativas em Adolescentes: Avaliação Auxiliar às Tomadas de Decisão. Psico, PUCRS, 44, 453-463.

Mészáros, I. (2008). A educação para além do capital. Tradução Isa Tavares. (2a ed.), Boitempo.

Neto, J. C. de S., \& Centolanza, C. A. (2010). Da prática do desvio ao protagonismo. Psico, PUCRS, 41, $128-136$.

Quinelatto Caparrós, R. F. (2013a). Entre saberes, sabores e desafios da tarefa educativa com jovens em conflito com a lei: como educadoras significam os processos educativos do espaço do programa de medidas socioeducativas em meio aberto. 2013. 174 fls. Dissertação (Mestrado em Educação). Universidade Federal de São Carlos. 
Research, Society and Development, v. 10, n. 10, e494101019270, 2021

(CC BY 4.0) | ISSN 2525-3409 | DOI: http://dx.doi.org/10.33448/rsd-v10i10.19270

Quinelatto, R. F. (2015b). O Programa de medidas socioeducativas em meio aberto: educação ou reprodução do aprendizado da rua? 235 fls. Tese (Doutorado em Educação). Universidade Federal de São Carlos.

Silva, A. N., \& Soares, F. A. P. (2020). A reprodução da desigualdade no ambiente escolar: Considerações sobre a formação e políticas educacionais. Research, Society and Development, 9 , e 41591211397.

Silva, R. A. da., \& Araújo, S. M. B. (2013). A representação da função paterna para instituições de auxílio a adolescentes em conflito com a lei. Psic. Clin. 25, $37-52$.

Solfa, G. C. (2008). Processos de Acesso, permanência e inclusão de crianças e adolescentes em situação de vulnerabilidade na rede municipal de ensino de São Carlos. 2008. 168 fls. Dissertação (Mestrado em Educação). Universidade de São Paulo. 